\title{
Protein phosphatase 2A-linked and -unlinked caspase-dependent pathways for downregulation of Akt kinase triggered by 4-hydroxynonenal
}

\author{
W Liu' ${ }^{1,2}$, AA Akhand1, K Takeda1, Y Kawamoto', M Itoigawa², \\ M Kato ${ }^{1}$, H Suzuki ${ }^{1}$, N Ishikawa ${ }^{2}$ and I Nakashima ${ }^{*, 1}$ \\ 1 Department of Immunology, Nagoya University Graduate School of Medicine, \\ Showa-ku, Nagoya, Japan \\ 2 Department of Pharmacology, Aichi Medical University School of Medicine, \\ Nagakute, Aichi, Japan \\ * Corresponding author: I Nakashima, Department of Immunology, Nagoya \\ University Graduate School of Medicine, 53 Tsurumai-cho, Showa-ku, Nagoya \\ 466-8550, Japan. Tel: +81-52-744-2134; Fax: +81-52-744-2972; \\ E-mail: inakashi@med.nagoya-u.ac.jp
}

Received 27.9.02; revised 30.1.03; accepted 10.2.03

Edited by M Miura

\begin{abstract}
We studied the signal pathways for regulation of serine/ threonine protein kinase Akt in Jurkat cells that had been treated with 4-hydroxynonenal (HNE) for caspase-dependent apoptosis induction. Treatment of cells with HNE led to a decrease in the level of Akt activity due to the dephosphorylation at Ser473, a major regulatory phosphorylation site. HNE-mediated dephosphorylation of Akt was prevented by a protein phosphatase $2 A$ (PP2A) inhibitor, okadaic acid, and by a caspase-3 inhibitor, DEVD-CHO. HNE treatment resulted in an increase in the total level of PP2A activity, release of active tyrosine-dephosphorylated PP2A from the cytoskeleton and PP2A-Akt association, which were all dependent on caspase-3 activation. These results suggest that the level of PP2A activity is at least in part determined by its tyrosine phosphorylation, which is dually controlled by okadaic acid-sensitive phosphatases and protein-tyrosine kinases. Possibly underlying the mechanism of caspase-mediated activation of PP2A, HNE treatment resulted in downregulation of the activity of Src kinase, as a representative caspase-sensitive kinase to phosphorylate PP2A at tyrosine. In addition, activated caspase-3 partially cleaved Akt at a late stage of the apoptosis. These results indicate the existence of two distinct caspasedependent signal pathways for downregulation of Akt that works as a mechanism of positive feedback regulation for HNEtriggered apoptotic signals.

Cell Death and Differentiation (2003) 10, 772-781. doi:10.1038/ sj.cdd. 4401238
\end{abstract}

Keywords: Akt; caspase-3; 4-hydroxynonenal (HNE); okadaic acid; protein phosphatase 2A (PP2A); Src

Abbreviations: DEVD-CHO, acetyl-Asp-Glu-Val-Asp aldehyde; DMEM, Dulbecco's modified Eagle's medium; HNE, 4-hydro- xynonenal; MBP, myelin basic protein; PDK1, 3'-phosphoinositide-dependent kinase-1; PP2A, protein phosphatase 2A; Ptyr, phosphotyrosine; SDS-PAGE, sodium dodecylsulfate-polyacrylamide gel electrophoresis.

\section{Introduction}

The growth and survival of cells in multicellular organisms require continuous stimulation from the extracellular environment. While extracellular signal-regulated kinase, a member of the mitogen-activated protein kinase family, is known to be an important mediator of growth factor-mediated cellular growth response, ${ }^{1}$ activation of Akt has recently been drawing attention due to its potential role in intracellular signaling pathways to prevent apoptosis and promote cell survival. ${ }^{2-5}$ Downstream targets of Akt include GSK- $3,{ }^{6}$ the $\mathrm{Bcl}-2$ family member Bad, ${ }^{7,8}$ the Forkhead family of transcription factors ${ }^{9-}$ ${ }^{11}$ and caspase- $9 .{ }^{12}$ Phosphorylation of these proteins by Akt prevents them from functioning proapoptotically, thereby favoring the survival-promoting effects of Akt. ${ }^{5-12}$

In response to mitogens and survival factors, Akt is activated through recruitment to the cellular membrane by $\mathrm{PI}-3$ kinase lipid products. ${ }^{13-15}$ During this activation process, Akt becomes phosphorylated at two major sites: Thr308 in the kinase domain and Ser473 in the carboxy-terminal tail. ${ }^{16}$ Initially, 3'-phosphoinositide-dependent kinase-1 (PDK1) was thought to phosphorylate only Thr308 of Akt; ${ }^{17,18}$ however, a recent study demonstrated the capability of PDK1, after interacting with a PDK1-interacting fragment, to phosphorylate both Thr308 and Ser473. ${ }^{19}$

In contrast to the activation of Akt associated with its phosphorylation by PDK1, downregulation of this serine/ threonine kinase is still not fully understood. Recently, Akt has been shown to be dephosphorylated at both Thr308 and Se473 and inactivated in vitro by protein phosphatase $2 \mathrm{~A}$ (PP2A), ${ }^{20-22}$ which forms a complex with Akt, ${ }^{23,24}$ and to be activated in cells upon treatment with the PP2A inhibitors such as okadaic acid, ${ }^{20-22}$ suggesting that PP2A is a major opponent of PDK1 in the regulation of Akt. PP2A is a multimeric serine/threonine phosphatase with a complex structure in which its catalytic $C$ subunit $(36 \mathrm{kDa})$ is tightly associated with a 65-kDa $A$ subunit forming the core enzyme. ${ }^{25}$ The $A$ subunit is a scaffold protein, the primary function of which is to recruit one of a variety of regulatory $B$ subunits. PP2A undergoes post-translational modification either by phosphorylation or by methylation. Phosphorylation occurs in the carboxyl terminus of the catalytic subunit at

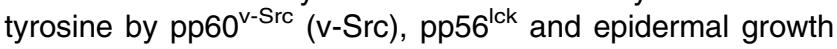
factor and insulin receptors, resulting in inactivation of the enzyme. ${ }^{26-28}$ However, the reported effects of methylation by methyltransferases in the carboxyl terminus of the PP2A 
catalytic subunit on its enzymatic activity are conflicting: moderate increase, ${ }^{29}$ no effect on ${ }^{30,31}$ or decrease in the activity. ${ }^{32}$ It is now known that carboxyl methylation of the catalytic subunit promotes its functional association with the regulatory subunits. ${ }^{31,33}$ In addition to Akt, some other protein kinases, including p70 S6 kinase, ${ }^{34}$ calmodulin kinase IV $^{35}$ and p21-activated kinase, ${ }^{34}$ have been identified as substrates of PP2A, some of which form stable complexes with PP2A.

4-Hydroxynonenal (HNE), a diffusible product of lipid peroxidation, has been suggested to play a key role in oxidative stress-induced cell death. We previously demonstrated that HNE induces cell growth inhibition ${ }^{36}$ and apoptotic cell death ${ }^{37}$ by targeting the epidermal growth factor receptor $(E G F R)^{36}$ and activating the caspase cascade in a redoxlinked way. ${ }^{37}$ In the present study, we found that Akt was downregulated in HNE-stimulated Jurkat cells. We also found that inactivation of Akt is due to dephosphorylation of a specific regulatory phosphorylation site (Ser473) by PP2A, the activity of which is elevated in a caspase-dependent manner.

\section{Results}

\section{HNE induces inactivation of Akt}

To determine possible changes in Akt activity during apoptosis, we stimulated Jurkat cells for an in vitro kinase assay with $20 \mu \mathrm{M}$ of HNE, an amount that induced apoptosis in our previous study. ${ }^{37} \mathrm{HNE}$ reduced the catalytic activity of Akt compared to that of the control as revealed by a decrease in the phosphorylation level of an exogenous substrate myelin basic protein (MBP) (Figure 1a). Interestingly, pretreatment of the cells with cysteine before HNE treatment, which prevented HNE-induced apoptosis, ${ }^{37}$ restored the activity of Akt to almost the background level. To further dynamically observe the progress of Akt inactivation, we performed a time-course

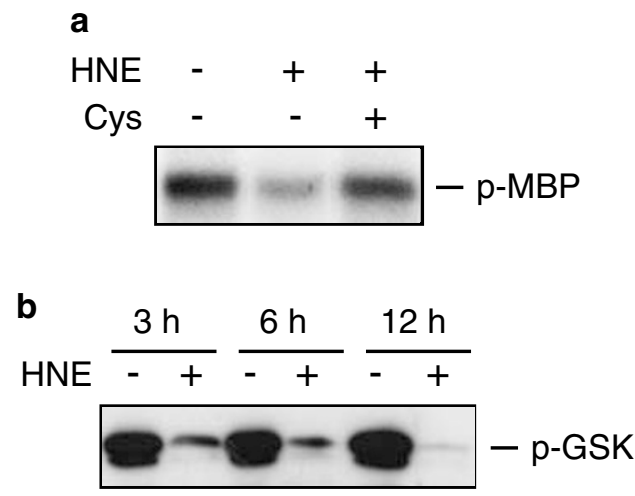

Figure $1 \mathrm{HNE}$ induces inactivation of Akt. Jurkat cells were incubated with or without $20 \mu \mathrm{M}$ of HNE at $37^{\circ} \mathrm{C}$ for $3 \mathrm{~h}$ (a) or the indicated times (b). In one group of $\mathrm{A}, 20 \mu \mathrm{M}$ of cysteine (Cys) was added $10 \mathrm{~min}$ prior to the addition of HNE. The cells were then lysed with lysis buffer, and the cell lysates were immunoprecipitated with anti-Akt antibody. The immunoprecipitates were examined for Akt activity by a radioactive in vitro kinase assay using MBP as an exogenous substrate (a) or by the use of a nonradioactive IP-kinase assay kit with GSK-3 as an exogenous substrate (b). Representative results of three experiments with consistent results are shown experiment to measure the activity of Akt with a nonradioactive IP-kinase assay kit using GSK-3 as a specific substrate of Akt. As shown in Figure 1b, Akt was inactivated at $3 \mathrm{~h}$ after HNE treatment, as revealed by a drastic reduction in GSK phosphorylation, and phospho-GSK was no longer detectable at $12 \mathrm{~h}$ after HNE treatment, suggesting almost complete inactivation of Akt at that time.

\section{Dephosphorylation of Akt at Ser473}

It is known that activation/inactivation of Akt depends on phosphorylation/dephosphorylation of the two major regulatory phosphorylation sites Ser473 and Thr308. ${ }^{16,21}$. We therefore measured the phosphorylation level of Akt using an antibody specific for either phosphoserine 473 or phosphothreonine 308. In untreated control cells, Akt was found to be constitutively phosphorylated at Ser473 at certain levels (Figure 2a). When the cells were treated with $20 \mu \mathrm{M}$ of HNE for $6 \mathrm{~h}$, a dramatic dephosphorylation of phospho-Ser473 was observed. Interestingly, this dephosphorylation of Akt at Ser473 was almost completely blocked by pretreating the cells with cysteine before HNE treatment. A time-course study with $20 \mu \mathrm{M}$ of HNE showed that dephosphorylation at Ser473 started at $3 \mathrm{~h}$ and intensified with prolongation of time (Figure 2b). However, 1-h stimulation did not induce dephosphorylation of Akt even with higher concentrations $(50-100 \mu \mathrm{M})$ of HNE used in this experiment (Figure 2c). These results demonstrated that HNE-induced dephosphorylation of Akt at Ser473 is time dependent. Intriguingly, no detectable phosphorylation at Thr308 of Akt developed in either HNEtreated or -untreated cells (Figure 2d), whereas phosphorylation at Thr308 of Akt was clearly detected by stimulating the cells with pervanadate, a potential stimulator of Akt. ${ }^{20}$ These results suggested that Akt activity in unstimulated Jurkat cells was maintained mainly by phosphorylation at Ser473, which was the preferential target of HNE for downregulation.

\section{Inhibition of PP2A or caspase-3 prevents Akt dephosphorylation}

Dephosphorylation of Akt by HNE led us to examine whether this dephosphorylation was mediated by PP2A, a key protein phosphatase that is responsible for dephosphorylation of Akt. $^{20-22}$ Pretreatment of the cells with okadaic acid, an inhibitor of PP2A, rescued Akt from HNE-mediated dephosphorylation at Ser473 partially by a relatively low concentration $(0.1 \mu \mathrm{M})$ and completely by a high concentration $(1 \mu \mathrm{M})$ (Figure 3a). This result suggested that PP2A was involved in the dephosphorylation process although it did not exclude the possibility of the involvement of other phosphatases such as PP1, PP4 and PP5, which are inhibited by low (in cases of PP2A, PP4, PP6) or high (in case of PP1) concentrations of okadaic acid. ${ }^{38-40}$ Since the result of time course of HNEinduced Akt dephosphorylation (Figure 2b) corresponded well to the time course of HNE-induced caspase activation in our earlier study, ${ }^{37}$ we carried out an experiment to determine whether dephosphorylation of Akt is a consequence of caspase activation. Pretreatment of the cells with a specific 
a

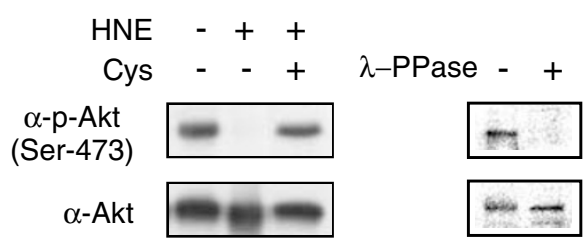

C

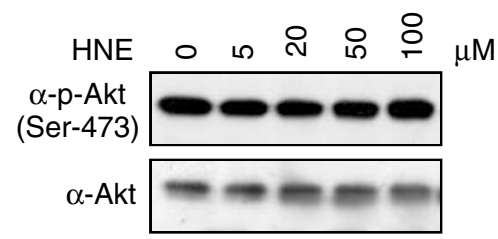

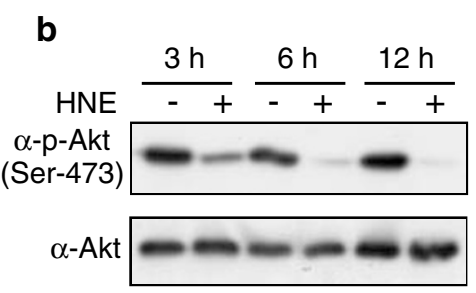

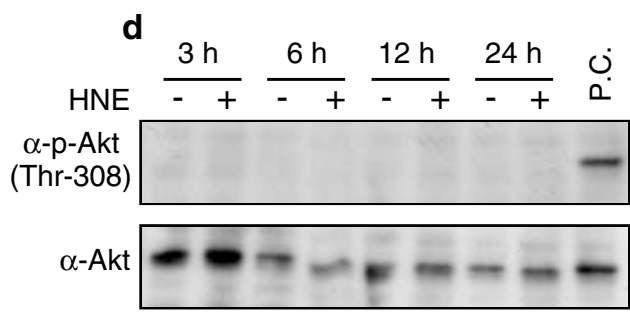

Figure 2 HNE induces dephosphorylation of Akt at Ser473. Jurkat cells were incubated with or without $20 \mu \mathrm{M}(\mathbf{a}, \mathbf{b}, \mathbf{c})$ or indicated concentrations $(\mathbf{c})$ of $\mathrm{HNE}$ at $37^{\circ} \mathrm{C}$ for $6 \mathrm{~h}(\mathbf{a}), 1 \mathrm{~h} \mathrm{(c)}$ or the indicated times (b, d). In one group of (a), $20 \mu \mathrm{M}$ of cysteine (Cys) was added 10 min prior to the addition of HNE. The cells were then lysed with sample buffer and subjected to immunoblot assay with Ser473-specific anti-phospho-Akt (a-c) or Thr308-specific phospho-Akt (d) antibody. Pervanadate was used as a positive control (PC) in the extreme right lane of (d). One of the two additional control samples shown in the right panel in (a) was pretreated with 1-PPase before the immunoblot assay as described in Materials and Methods to demonstrate that the phospho-signals obtained with phospho-antibodies are specific and are due to protein phosphorylation. Phospho-Akt membranes were stripped and reprobed with an anti-Akt antibody, which confirmed equal loading of proteins. Representative results of three experiments with consistent results are shown

a

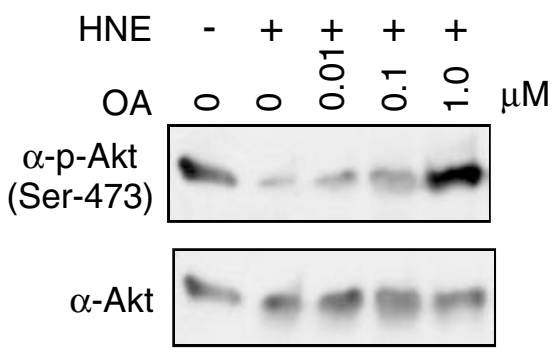

b

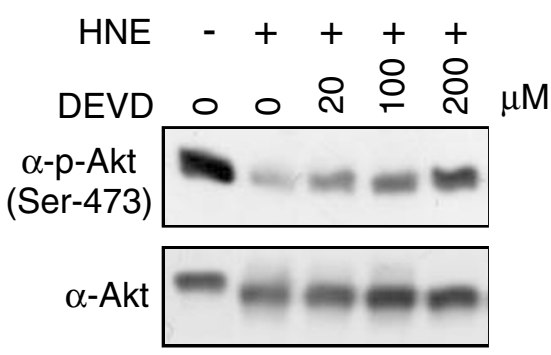

Figure 3 HNE-mediated dephosphorylation of Akt is prevented by inhibitors of PP2A or caspase. Jurkat cells were preincubated with indicated concentrations of $\mathrm{OA}$ (a) or DEVD-CHO (b) for $1 \mathrm{~h}$ and exposed to $20 \mu \mathrm{M}$ of HNE for $3 \mathrm{~h}$ at $37^{\circ} \mathrm{C}$. The cells were then lysed with sample buffer and subjected to immunoblot assay with Ser473-specific anti-phospho-Akt antibody. Phospho-Akt membranes were stripped and reprobed with anti-Akt antibody, which confirmed equal loading of proteins. Representative results of three experiments with consistent results are shown

caspase-3 inhibitor, DEVD-CHO, resulted in a gradual reversal of $\mathrm{HNE}$-induced Akt dephosphorylation with increase in the dose of the inhibitor (Figure $3 b$ ). These results suggested that dephosphorylation of Akt at Ser473 was caspase-dependent.

\section{Interaction of PP2A with Akt}

As shown in Figure $4 \mathrm{a}$, a low but detectable amount of the catalytic subunit of PP2A was co-precipitated with Akt in untreated cells, indicating the occurrence of a physiological association of these two proteins. This observation agrees with recently reported findings that PP2A and Akt form a complex for efficient PP2A activity. ${ }^{23,24}$ Interestingly, PP2A-Akt association was greatly promoted by HNE after $3 \mathrm{~h}$ of incubation (Figure 4a), when Akt was actually dephosphorylated drastically (Figure $2 b$ ). In addition, pretreatment of the cells with DEVO-CHO or okadaic acid before HNE treatment almost completely blocked PP2A-Akt association (Figure 4b). These data suggested that PP2A mediated Akt dephosphorylation by directly associating with Akt and that this mechanism was also caspase-dependent.

To confirm the involvement of PP2A in the process of HNEmediated Akt dephosphorylation, we next carried out an experiment to determine whether the overall catalytic activity of PP2A was upregulated after HNE treatment. Using a nonradioactive serine/threonine phosphatase assay kit with the phosphopeptide K-R-pT-I-R-R as a substrate, ${ }^{41}$ we measured the amount of released phosphate, which indicates the overall phosphatase/PP2A activity. HNE treatment caused an increase in phosphate release, indicating elevated PP2A activity, which was blocked by pretreating the cells with a relatively low concentration of okadaic acid (Figure 5). In addition, a caspase inhibitor, DEVD-CHO, also inhibited the HNE-mediated increase in phosphate release. 
a

$$
\begin{gathered}
\text { HNE }-+ \\
-\infty \text { IP: } \alpha \text {-Akt, IB: } \alpha \text {-PP2A/C } \\
- \text { IP: } \alpha \text {-Akt, IB: } \alpha \text {-Akt }
\end{gathered}
$$

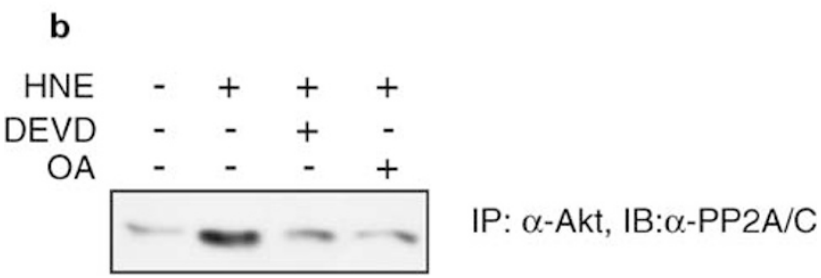

Figure 4 HNE induces binding of Akt with PP2A. Jurkat cells were incubated with or without $20 \mu \mathrm{M}$ of HNE for indicated $3 \mathrm{~h}$ at $37^{\circ} \mathrm{C}$. In some groups of (b), $0.1 \mu \mathrm{M}$ of OA or $100 \mu \mathrm{M}$ of DEVD-CHO was added $1 \mathrm{~h}$ prior to the addition of HNE. The cells were then lysed with RIPA buffer for immunoprecipitation with anti-Akt antibody followed by immunoblot assay with anti-PP2A/C and anti-Akt antibodies. Representative results of three experiments with consistent results are shown

\section{Activation of caspases does not induce obvious proteolysis of PP2A}

The finding of requirement of both caspase and PP2A for HNE-induced dephosphorylation of Akt led us to investigate their possible relation in this process. It is known that the regulatory $A$ subunit of PP2A either inhibits or stimulates the catalytic $C$ subunit depending on the reaction conditions and on the size and type of the substrate. ${ }^{42} A$ recent study has shown that PP2A is activated through cleavage of its $A$ subunit by caspase-3 in Fas-induced apoptosis. ${ }^{43}$ We carried out an experiment to determine whether treatment with HNE, which activates caspases, ${ }^{37}$ could lead to proteolysis of the A subunit linked to the increased PP2A activity. As shown in Figure 6, however, no obvious cleavage of the A subunit was detected at any time points tested from 3 to $24 \mathrm{~h}$, demonstrating that HNE-mediated activation of PP2A might not primarily involve caspase-mediated degradation of the A subunit. The levels of the catalytic subunit also remained unchanged at these same times.

\section{HNE promotes release of tyrosine- dephosphorylated PP2A}

It has been demonstrated that PP2A directly binds to cytoskeletal microtubules in vitro and in cells. ${ }^{44-46}$ The binding of PP2A with assembled tubulin results in an inhibition of its catalytic activity, while disassembly of microtubules may result in the release and activation of PP2A. We carried out an experiment to determine whether HNE-induced upregulation of PP2A activity was associated with its increased release from PP2A-microtubule complexes. After lysing of the cells with lysis buffer, cell lysates were centrifuged to separate the supernatant and the pellet (containing cytoskeletal proteins) fractions. The supernatants were immunoprecipitated with

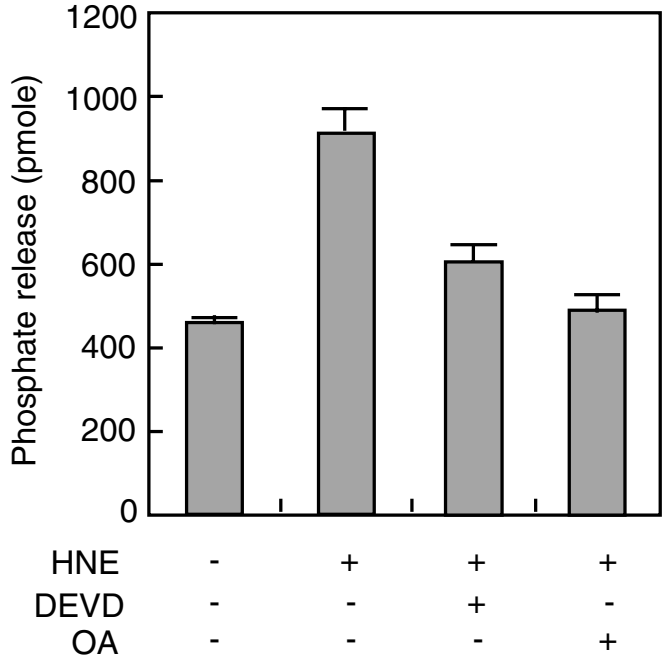

Figure 5 HNE upregulates PP2A activity. Jurkat cells were preincubated with or without $0.1 \mu \mathrm{M}$ of OA or $100 \mu \mathrm{M}$ of DEVD-CHO for $1 \mathrm{~h}$ and exposed to $20 \mu \mu \mathrm{M}$ of HNE for $3 \mathrm{~h}$ at $37^{\circ} \mathrm{C}$. PP2A activity with the cellular proteins extracted from RIPA buffer-lysed cells was measured using phosphopeptide K-R-pT-I-R-R as a substrate as described in Materials and Methods. Each column represents the mean \pm S.D. of triplicate assays

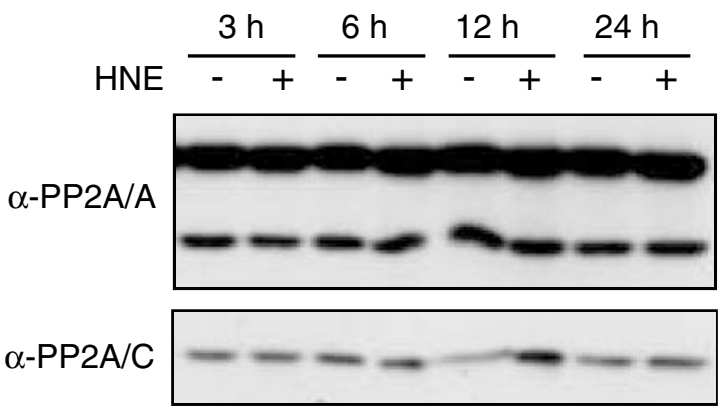

Figure 6 HNE does not induce obvious cleavage of the A subunit of PP2A. Jurkat cells were incubated with $20 \mu \mathrm{M}$ of HNE for indicated times at $37^{\circ} \mathrm{C}$. The cells were then lysed with sample buffer and subjected to immunoblot assay with an A subunit-specific anti-PP2A/A antibody (top panel), which developed a PP2A-specific thick band (upper) and a nonspecific thin band (lower). The membrane was stripped and reprobed with a $C$ subunit-specific anti-PP2A/C antibody (bottom panel). Representative results of three experiments with consistent results are shown

anti-PP2A antibody, and the pellets were directly dissolved in sample buffer. As shown in Figure 7, the amount of PP2A immunoprecipitated from the supernatant of HNE-treated cells was increased compared to that immunoprecipitated from the supernatant of untreated cells (top panel); conversely, the amount of $\mathrm{PP} 2 \mathrm{~A}$ remaining in the tubulincontaining (fifth panel from the top) pellet (third panel) was decreased, suggesting promoted relocalization of PP2A from the detergent-insoluble pellet to the soluble supernatant fraction. PP2A protein levels in the detergent-insoluble pellet fraction decreased following the HNE treatment in association with a reduction in the levels of tyrosine phosphorylation of the protein bands (fourth panel), suggesting a connection 


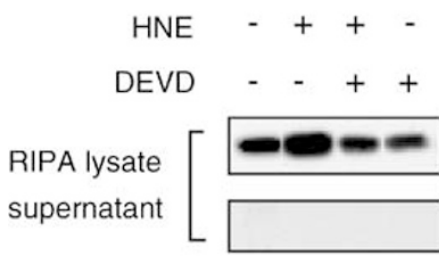

IP \& Blot: $\alpha-P P 2 A / C$

IP: $\alpha-\mathrm{PP} 2 \mathrm{~A} / \mathrm{C}, \mathrm{Blot}: \alpha-\mathrm{P}$-tyr
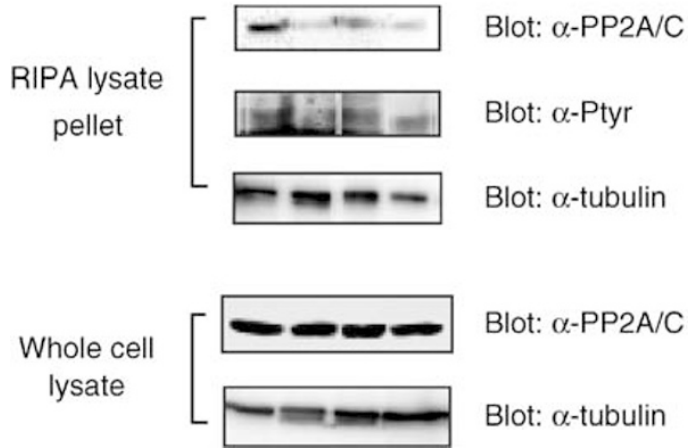

Figure 7 HNE promotes release of tyrosine-dephosphorylated PP2A. Jurkat cells were incubated with or without $20 \mu \mathrm{M}$ of $\mathrm{HNE}$ for $6 \mathrm{~h}$ at $37^{\circ} \mathrm{C}$. In some groups, $100 \mu \mathrm{M}$ of DEVD-CHO was added $1 \mathrm{~h}$ prior to the addition of HNE. The cells were then lysed with RIPA buffer and centrifuged to separate supernatant (detergent-soluble) and pellet (detergent-insoluble) fractions. Anti-PP2A antibody was added to the supernatant for immunoprecipitation, and sample buffer was added to the pellet to dissolve pelleted proteins. Immunoblot assay was performed using anti-PP2A/C antibody with these samples together with a set of whole-cell lysate samples (panels 1, 3 and 6 from the top). PP2A/C membranes were stripped and reprobed with anti-Ptyr antibody (panels 2 and 4 from the top) and anti-tubulin antibody (panels 5 and 7). Representative results of four experiments with consistent results are shown

between PP2A protein release from the pellet fraction and its dephosphorylation. Intriguingly, this HNE-induced promotion of the release of PP2A from the detergent-insoluble fraction to the detergent-soluble fraction was prevented by DEVD-CHO. Examination of the whole-cell lysates showed equal amounts of PP2A and tubulin in all HNE-treated and -untreated cells (sixth and seventh panels), which normalized original sample amounts before fractionation.

Since it was reported previously that PP2A is inactivated through in vitro tyrosine phosphorylation by the Src family or other protein-tyrosine kinases, ${ }^{26-28}$ we examined the tyrosine phosphorylation levels of PP2A in the above samples. As also shown in Figure 7, no staining for tyrosine phosphorylation was observed on any bands for PP2A from the supernatants (second panel from the top), whereas we detected positive staining on PP2A bands from the pellet (fourth panel from the top). HNE treatment of the cells resulted in a reduction in the level of tyrosine phosphorylation of the PP2A band from the pellet (lane 2 from the left) compared with that of the control (lane 1), and this reduced level was restored by preincubation with DEVD-CHO (lane 3 ). These results suggest that PP2A is bound to cytoskeletal proteins in close association with its tyrosine phosphorylation, that inactivation and dephosphorylation causes release of PP2A to the cytosol for activation, and that HNE causes reduction of the tyrosine phosphorylation level of PP2A for its cytosolic release and activation through a caspase-dependent mechanism.

\section{HNE downregulates the catalytic activity of Src}

It has been reported that tyrosine phosphorylation of PP2A is induced in the carboxyl terminus of the catalytic subunit by a number of protein-tyrosine kinases, including $\mathrm{v}$-Src. ${ }^{26,27}$ Using cells expressing v-Src at a high level, we tested the hypothesis that HNE-induced activation of caspase could lead to downregulation of the catalytic activity of protein-tyrosine kinases, represented by v-Src. As shown in Figure 8, HNE caused reduction of the kinase activity of $\mathrm{v}$-Src as indicated by a decrease in autophosphorylation and phosphorylation of enolase as an exogenous substrate at the time when cytosolic release and activation of PP2A was increased. This HNEmediated reduction of $\mathrm{v}$-Src kinase activity was prevented by DEVD-CHO, demonstrating a role of caspase in the mechanism.

\section{Degradation of Akt}

In addition to the abovementioned dephosphorylation/ inactivation of Akt by a PP2A/caspase-dependent mechanism, caspase might also directly attack Akt for degradation. We tested this possibility using an anti-Akt antibody that recognizes both the intact protein and the cleaved fragments. We found that within $6 \mathrm{~h}$ after HNE stimulation, at which time significant dephosphorylation and inactivation of Akt had occurred, no obvious proteolysis of Akt had occurred (Figure 9a). However, when the cells were stimulated by HNE for a longer time, clearly cleaved fragments of Akt were detected. This Akt degradation was blocked by DEVD-CHO but not by okadaic acid (Figure 9b). These results suggest that HNE-induced degradation of Akt at a later stage is caspase-3dependent but PP2A-independent.

\section{Discussion}

In this study, we demonstrated that the lipid peroxidation product HNE induced dephosphorylation and inactivation of Akt at the second stage (Figures 1 and 2) following the previously reported ${ }^{37}$ first-stage event for initial activation of caspase-3. Mitogens/growth factors-induced activation of Akt coupled with its phosphorylation at Thr308 and Ser473 is known to prevent apoptosis by mediating phosphorylation of a number of downstream targets, including GSK-3/Bad/caspase- $9,{ }^{6,7,10}$ which ultimately promotes cell survival. ${ }^{2-5}$ Akt activation by insulin-like growth factor 1 involves phosphor-

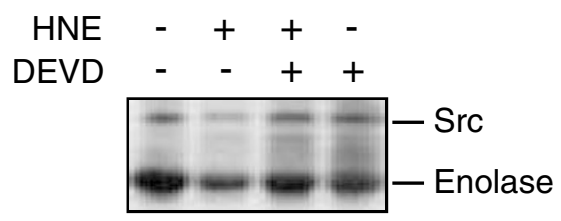

Figure 8 HNE downregulates Src kinase activity. NIH3T3 cells with a high leve of v-Src expression were incubated with or without $20 \mu \mathrm{M}$ of HNE at $37^{\circ} \mathrm{C}$ for $6 \mathrm{~h}$. In some groups, $100 \mu \mathrm{M}$ of DEVD-CHO was added $1 \mathrm{~h}$ prior to the addition of HNE. The cells were then lysed with RIPA buffer, and the cell lysates were immunoprecipitated with anti-Src antibody. The immunoprecipitates were examined for Src kinase activity by a radioactive in vitro kinase assay using enolase as an exogenous substrate 
a

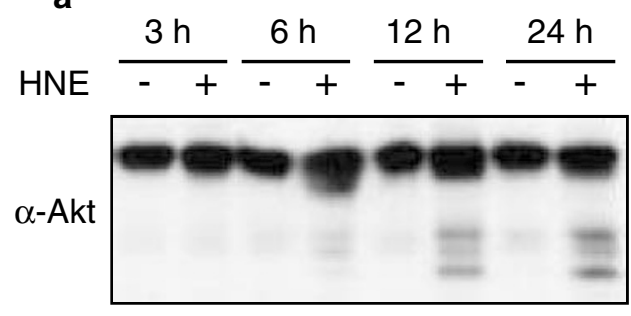

b

$\begin{array}{rrrrr}\text { HNE } & - & + & + & + \\ \text { OA } & - & - & + & - \\ \text { DEVD } & - & - & - & +\end{array}$
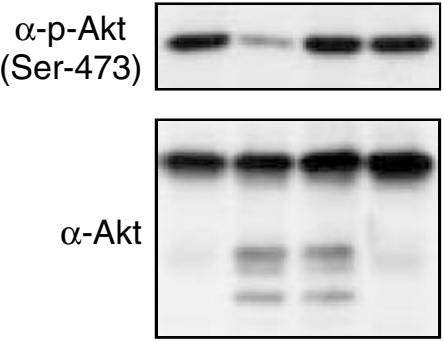

Figure 9 HNE induces cleavage of Akt. Jurkat cells were incubated with or without $20 \mu \mathrm{M}$ of HNE for indicated times (a) or $3 \mathrm{~h}(\mathbf{b})$ at $37^{\circ} \mathrm{C}$. In some groups of (b) $0.1 \mu \mathrm{M}$ of OA or $100 \mu \mathrm{M}$ of DEVD-CHO was added $1 \mathrm{~h}$ prior to the addition of HNE. The cells were then lysed with sample buffer and subjected to immunoblot assay with anti-Akt or with Ser473-specific anti-phospho-Akt antibody. Representative results of three experiments with consistent results are shown

ylation at both Ser473 and Thr308, ${ }^{16}$ whereas Akt activation by TNF- $\alpha$ involves phosphorylation at Ser473 but not at Thr308. ${ }^{47}$ The results of the present study suggest that Ser473, but not Thr308, of Akt, is constitutively phosphorylated in Jurkat cells, potentially for maintaining their survival, and that the Akt activity is downregulated by treatment of the cells with HNE (Figure 1) through dephosphorylation of Ser473 (Figure 2). We previously showed that treatment of Jurkat cells with HNE-induced activation of caspase-3, leading to cellular apoptosis. ${ }^{37}$ In the present study, we demonstrated that the HNE-mediated promotion of Akt Ser473 dephosphorylation was caspase-3-dependent (Figure 3). Therefore, it is thought that the observed HNE-mediated Akt inactivation works as a positive feedback regulation of the once-started HNE-mediated caspase-dependent pathway for apoptosis.

Since Akt was previously reported to be dephosphorylated and inactivated by PP2A in vitro, ${ }^{20-22}$ we examined the involvement of PP2A in HNE-mediated dephosphorylation of Akt. Our results showing the rescue of HNE-mediated dephosphorylation of Akt by the PP2A inhibitor okadaic acid (Figure 3 ) led us to assume that PP2A plays a role in the process of this dephosphorylation. Since okadaic acid inhibits not only PP2A but also PP1, PP4 or PP5, ${ }^{38-40}$ there remains the possibility that multiple phosphatases are involved in the mechanism, although 1,2-dioleoyl-sn-glycero-3-phosphate, an inhibitor of $\mathrm{PP} 1{ }^{48}$ did not obviously inhibit the phosphatase activity on phospho-Akt (Liu et al., unpublished data). The assumption that PP2A plays a key role in the regulation of Akt, whether or not other phosphatases are additionally involved, was, however, supported by the finding of HNE-induced increase in binding of Akt with PP2A (Figure 4), through a relatively low concentration of okadaic acid-sensitive mechanism, that might have favored the enzyme (PP2A)-substrate (Akt) reaction for dephosphorylation. Correspondingly, we showed that treatment of the cells with HNE induced an overall increase in the level of a relatively low concentration of okadaic acid-sensitive PP2A activity in the detergent-soluble membrane/cytosol fraction of cell lysates to dephosphorylate the phosphopeptide K-R-pT-R-R (Figure 5). What could then be the molecular mechanism of HNE-induced increase in okadaic acid-sensitive cellular PP2A activity? We showed that HNE-mediated promotion of Akt (Ser473) dephosphorylation, formation of a complex between Akt and PP2A and overall increase in cellular phosphatase/PP2A activity are all prevented by the addition of DEVD-CHO as a caspase inhibitor. Santoro et al. ${ }^{43}$ recently reported that caspase-3 regulates the activity of PP2A during anti-Fas antibody apoptosis. They showed that caspase- 3 cleaves the regulatory $A$ subunit of PP2A in anti-Fas antibody-treated Jurkat cells, resulting in its activation. However, unlike the anti-Fas antibody, HNE did not detectably induce degradation of the regulatory $A$ subunit of PP2A at any time during the period of 3-24 $\mathrm{h}$ after HNE treatment (Figure 6).

It is possible that some cleavage that was not detectable by the method we used, but was efficient for modifying the regulatory activity of the subunit, upregulated the PP2A activity in HNE-treated cells. Further study has, however, demonstrated an alternative, though not mutually exclusive, mechanism for HNE-mediated upregulation of PP2A activity. We found that HNE induced an increase in the release of PP2A into the detergent-soluble fraction of cell lysates from the detergent-insoluble fraction (Figure 7) in association with an increase in catalytic activity of PP2A in the former fraction (Figure 5). Recently, Hiraga and Tamura ${ }^{44}$ and Sontag et al. ${ }^{45,46}$ have demonstrated that PP2A could directly be bound to microtubules/cytoskeletal proteins in vitro and in cells. They further showed that interaction of PP2A with assembled tubulins inhibited its catalytic activity, whereas disassembly of microtubules resulted in the release of PP2A into the cytosol in a form with strong catalytic activity. The results of our study have provided for the first time, evidence that the level of tyrosine phosphorylation of PP2A at tyrosine primarily determines its intracellular localization; tyrosine-phosphorylated PP2A was bound to the cytoskeleton, the dephosphorylation of which caused its release from the cytoskeleton.

We demonstrated that the mechanism of HNE-mediated release of an active form of tyrosine-dephosphorylated PP2A from the detergent-insoluble fraction to the detergent-soluble fraction was caspase-dependent (Figure 7). Tyrosine phosphorylation levels of PP2A are thought to be regulated by both protein-tyrosine kinase and okadaic acid-sensitive phosphatase activities, including PP2A activity itself, for autodephosphorylation. ${ }^{26,49}$ Some cleavage of the regulatory or catalytic subunits of PP2A, which we failed to demonstrate in this study (Figure 6), might promote the PP2A activity for autodephosphorylation. However, the mechanism of the caspasedependent HNE-mediated upregulation of PP2A activity 
may also involve the control of protein-tyrosine kinases such as $\mathrm{v}$-Src, which phosphorylates PP2A at tyrosine in the carboxyl terminal of the catalytic subunit. ${ }^{26,27}$ In support of this view, we showed that the catalytic activity of $\mathrm{v}-\mathrm{Src}$, a representative of protein-tyrosine kinases that phosphorylate PP2A, ${ }^{26,27}$ was downregulated in a caspase-dependent manner in the HNE-treated cells around the time when the PP2A activity was upregulated (Figure 8). The details of the mechanism of caspase-dependent downregulation of Src kinase in HNE-treated cells remain to be clarified. However, it has been reported that Src proteins can be the substrate of caspase-3 to be cleaved at its C-terminal portion for inactivation. ${ }^{50}$ Taken together, the results suggest that HNE-induced activation of caspase at the first stage ${ }^{37}$ leads to downregulation of $\mathrm{Src}$ and potentially other protein-tyrosine kinases at the second stage, possibly through its cleavage by caspase, which reduces the level of tyrosine phosphorylation of PP2A and thereby promotes its release from the cytoskeleton and catalytic activity to dephosphorylate Akt for inactivation. Furthermore, we demonstrated that the caspase/ PP2A-dependent mechanism of Akt dephosphorylation and inactivation, which worked during the period from 3 to $6 \mathrm{~h}$ after HNE treatment, was followed by a caspase-dependent but PP2A-independent mechanism for direct Akt degradation at a later stage. We therefore conclude that the HNE-triggered signal pathway for caspase activation at the first stage is subjected to two distinct (PP2A-linked and -unlinked) positive feedback regulations through downregulation of Akt at the second stage, as illustrated in Figure 10.

Oxidative stress-linked increased production of HNE is believed to be an important factor in the development of a number of diseases, such as atherosclerosis, diabetes and age-related neurodegenerative diseases such as Alzheimer's disease ${ }^{51-54}$ HNE may change cellular functions in different steps, which may collectively work for an ultimate goal of disease progression. HNE is highly reactive with proteins and glutathiones, and it easily forms HNE-protein adducts and consumes the cellular glutathione pool. ${ }^{37,55}$ We have shown in earlier studies that these properties of HNE cause protein-tyrosine kinase activation through the formation of an HNE-cell surface protein adduct on the one hand ${ }^{37}$ and triggering the caspase cascade through depletion of the glutathione pool on the other. ${ }^{37}$ The present study has newly demonstrated a connection between these two HNE actions in such a way as HNE-mediated caspase activation leads to downregulation of initially HNE-stimulated protein-tyrosine kinases as a feedback regulation, which ultimately promotes HNE-mediated caspase activation for apoptosis induction. Whereas the previously reported first-stage actions of HNE require direct interactions of HNE with target cellular molecules, such as cell surface receptors, for inducing activation of protein tyrosine kinases ${ }^{36}$ and with the glutathione pool for triggering the redox-linked signal for the initial activation of caspase $-3,{ }^{37}$ the secondstage actions of HNE newly demonstrated in the present study, which trigger early and late signal pathways for downregulation of Akt, seem to primarily involve the action of caspase-3, the activity level of which has been elevated by the first-stage action of HNE (Figure 10). In short, all the results we obtained in the present study suggest novel

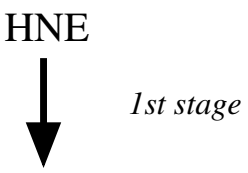

Caspase-3 (positive feedback regulation) (activation)

2nd stage

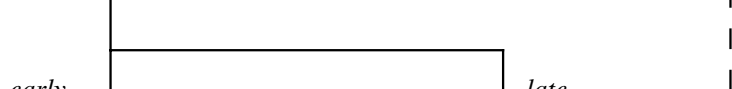

$\underline{\text { early }} \perp \quad$ late

Tyrosine kinase (Src etc) (downregulation)

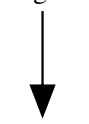

PP2A

(Decreased tyrosine phosphorylation/ cytosolic translocation/ activation)

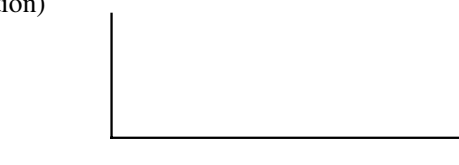

(dephosphorylation at Ser473)

Figure 10 A diagram of early and late caspase-3-dependent signal pathways for downregulation of Akt activity. Activated caspase-3, which was induced by direct HNE action at the first stage, triggered early (PP2A-linked) and late (-unlinked) signals for downregulation of Akt at the second stage

pathways for positive feedback regulation of the caspase-3dependent signal for induction of cellular apoptosis.

\section{Materials and Methods}

\section{Cell culture and stimulation}

Human T-cell leukemia Jurkat cells were cultured in RPMI-1640 medium (Sigma, St. Louis, MO,USA) supplemented with 10\% heat-inactivated fetal bovine serum (ThermoTrace, Melbourne, Australia), $100 \mathrm{U} / \mathrm{ml}$ penicillin and $100 \mu \mathrm{g} / \mathrm{ml}$ of streptomycin. Cultures were maintained at $37^{\circ} \mathrm{C}$ in a humidified $5 \% \mathrm{CO}_{2}$ atmosphere. Before stimulation, the cells were washed with serum-free RPMI medium and then incubated in serum-free medium with stimulators before use. For some experiments, NIH3T3 cells transformed with v-Src were used. These cells were cultured in the same way using Dulbecco's modified Eagle's medium (DMEM) (Sigma) instead of RPMI-1640 medium. Confluent cells were collected with $0.25 \%$ trypsin and $0.01 \%$ EDTA in phosphate-buffered saline and were split into $60-\mathrm{mm}$ plastic plates with DMEM containing $10 \%$ fetal bovine serum for a further 20-24-h incubation. The cells were then rinsed with fresh modified Eagle's medium twice and incubated in modified Eagle's medium at $37^{\circ} \mathrm{C}$ for $1 \mathrm{~h}$ before use.

\section{Reagents and antibodies}

HNE was obtained from Cayman Chemical (Ann Arbor, USA). The caspase-3 inhibitor DEVD-CHO was purchased from Kamiya Biomedical 
Company (Seattle, USA), and the PP2A inhibitor okadaic acid was purchased from RBI (Natick, USA). Polyclonal anti-Akt, antiphospho-Akt (Thr308) and antiphospho-Akt (Ser473) antibodies were purchased from Cell Signaling (Beverly, USA). Monoclonal anti-PP2A specific for the catalytic $C$ subunit and caspase-3 antibodies were purchased from Transduction Laboratories (Lexington, USA). Polyclonal anti-PP2A specific for the regulatory $A$ subunit was purchased from Chemicon International (Temecula, USA). Monoclonal anti-phosphotyrosine (Ptyr) antibody was purchased from Upstate Biotechnology (Lake Placid, NY, USA). Monoclonal anti-Src antibody was kindly donated by Dr JS Brugge (State University of New York, Albany, NY). ${ }^{56}$ Monoclonal rat antitubulin antibody was obtained from Oxford Biotechnology Limited, Oxford. Goat anti-rabbit/anti-mouse/anti-rat antibodies conjugated with horse-radish peroxidase, which were used as second antibodies in immunoblotting, were purchased from Bioscience International (Rockville, MD, USA). All the phospho-dependent antibodies for Western blots were tested on control cell samples pretreated with alkaline phosphatase (see below), the results of which confirmed that the signal obtained with these antibodies is due to protein phosphorylation (an example of data is included in Figure 2).

\section{Electrophoresis and immunoblotting}

Sodium dodecylsulfate-polyacrylamide gel electrophoresis (SDS-PAGE) and immunoblotting were performed as described previously. ${ }^{36}$ Whole cells, the pellet fraction of lysis buffer $(30 \mathrm{mM}$ Tris- $\mathrm{HCl}(\mathrm{pH} 7.5), 1 \%$ Triton $X-100,150 \mathrm{mM} \mathrm{NaCl}, 1 \mathrm{mM}$ EDTA, $0.5 \mathrm{mM}$ sodium orthovanadate and $1 \mathrm{mM}$ phenylmethylsulfonyl fluoride)-lysed cells (see below) or proteins immunoprecipitated from the supernatant fraction of lysis buffer-lysed cells (see below) were dissolved in SDS-sample buffer $(62.5 \mathrm{mM}$ Tris- $\mathrm{HCl}, \mathrm{pH}$ $6.8,2 \%$ SDS, $5 \% 2$-mercapto ethanol, $10 \%$ glycerol) followed by boiling for $3 \mathrm{~min}$ to denature the proteins. For dephosphorylated sample preparation, $400 \mathrm{U}$ of Lambda Protein Phosphatase (I-PPase; New England Biolabs, Beverly, MA, USA) was added to the cell lysate prepared in I-PPase buffer (50 mM Tris-HCl (pH 7.5), 0.1mM Na ${ }_{2}$ EDTA, $5 \mathrm{mM}$ dithiothreitol, $0.01 \%$ Brij 35, $2 \mathrm{mM} \mathrm{MnCl}_{2}$ ), and the mixture was incubated at $30^{\circ} \mathrm{C}$ for $30 \mathrm{~min}$. Proteins thus obtained were subjected to SDS-PAGE with $10 \%$ gel and were transferred to a polyvinylidene difluoride membrane. The membrane was incubated with blocking buffer (5\% nonfat dry milk or $3 \%$ bovine serum albumin) at $4^{\circ} \mathrm{C}$ overnight followed by incubation with a specific first antibody for $2-3 \mathrm{~h}$ at room temperature. After washing, the membrane was incubated with an appropriate second antibody for $1-2 \mathrm{~h}$. The proteins in the membrane were visualized by Western Blot Chemiluminescence Reagent (DuPont NEN, Boston, MA, USA), as directed by the manufacturer. The molecular sizes of the developed proteins were estimated by comparison with prestained protein markers (New England Biolabs).

\section{Immunoprecipitation}

Cells were lysed with ice-cold lysis buffer, and the lysates were separated by centrifugation at $15000 \times g$ for $15 \mathrm{~min}$ into the supernatant (detergentsoluble membranous/cytosolic proteins) and pellet (detergent-insoluble cytoskeletal proteins) fractions. For immunoprecipitation, anti-Akt, antiPP2A or anti-Src antibodies were added to the supernatant, and the immunoprecipitates were collected by incubating with protein $A$ sepharose beads (Pierce, Rockford, IL, USA). The beads bearing the immunoprecipitates were washed three times with ice-cold lysis buffer and used for either immunoblotting or in vitro kinase assay.

\section{In vitro kinase assay}

The immunoprecipitates that were collected as described above were washed three times with kinase buffer (10 mM Tris- $\mathrm{HCl}(\mathrm{pH} 7.4), 5 \mathrm{mM}$ $\mathrm{MgCl}_{2}$ ). The pellet thus obtained was used for assaying Akt or Src kinase activity by suspending it in $30 \mu \mathrm{l}$ of kinase buffer containing $2.0 \mu \mathrm{g}$ of MBP (Sigma) or enolase (Sigma) and radiolabeled $\left(\gamma{ }^{32}\right.$ P)ATP $(370 \mathrm{kBq})$ (NEN, Wilmington, DE, USA). The kinase reaction was carried out for $20 \mathrm{~min}$ at $30^{\circ} \mathrm{C}$ and was stopped by adding SDS-sample buffer. The samples were seperated on a $10 \%$ (for $\mathrm{Src}$ ) or $13 \%$ (for Akt) SDS-polyacrylamide gel, and the gel was exposed to X-ray film at $-80^{\circ} \mathrm{C}$ for autoradiography after drying.

Akt kinase assay was also performed using a nonradioactive IP-kinase assay kit (Cell Signaling, Beverly, USA) as directed by the manufacturer. Briefly, immunoprecipitated Akt was incubated with cold ATP and GSK-3 fusion protein, an Akt substrate, followed by detection of phosphorylated GSK-3 by immunoblotting with a specific antiphospho-GSK-3 $\alpha / \beta$ (Ser21/ 9) antibody.

\section{Determination of PP2A activity}

PP2A activity was determined by the use of a nonradioactive, malachite green-based serine/threonine phosphatase assay kit (Upstate Biotechnology, Lake Placid, NY, USA) as previously described. ${ }^{41}$ Briefly, $5 \mu \mathrm{g}$ of cellular proteins extracted in lysis buffer were incubated with $175 \mu \mathrm{M}$ of the phosphopeptide (K-R-pT-I-R-R) and PP2A buffer (20 mM MOPS, pH7.5, $60 \mathrm{mM}$ 2-ME, $0.1 \mathrm{M} \mathrm{NaCl}$ and $0.1 \mathrm{mg} / \mathrm{ml}$ serum albumin) in a total volume of $25 \mu \mathrm{l}$. Reactions were started by the addition of the phosphopeptide substrate and conducted for $10 \mathrm{~min}$ at room temperature. The reactions were terminated by the addition of malachite green solution, and then the solution was left for $15 \mathrm{~min}$ to allow for color development. The plate was then read at $650 \mathrm{~nm}$ with a microplate reader, and the amount of phosphate released was calculated from a standard curve. The reaction buffer and phosphorylated substrate in this assay have been designed to detect PP2A, but this assay may not fully discriminate between PP2A and PP1. ${ }^{41}$ Therefore, the sensitivity of measured phosphatase activity to $0.1 \mu \mathrm{M}$ okadaic acid, which inhibits PP2A but not PP1, was checked for the assay.

\section{Acknowledgements}

This work was supported in part by Grants-in-aid for Scientific Research B and Scientific Research of priority Areas from the Ministry of Education, Science, Sports and Culture of Japan and by the funds for comprehensive research on aging and health from the Ministry of Health and Welfare of Japan.

\section{References}

1. Seger $R$ and Krebs EG (1995) The MAPK signaling cascade. FASEB J. 9: 726735

2. Downward J (1998) Mechanisms and consequences of activation of protein kinase B/Akt. Curr. Opin. Cell. Biol. 10: 262-267

3. Wang X, McCullough KD, Franke TF, Holbrook NJ (2000) Epidermal growth factor receptor-dependent Akt activation by oxidative stress enhances cell survival. J. Biol. Chem. 275: 14624-14631

4. Marte BM and Downward J (1997) PKB/Akt: connecting phosphoinositide 3kinase to cell survival and beyond. Trends Biochem. Sci. 22: 355-358

5. Dudek H, Datta SR, Franke TF, Birnbaum MJ, Yao R, Cooper GM, Segal RA, Kaplan DR and Greenberg ME (1997) Regulation of 
neuronal survival by the serine-threonine protein kinase Akt. Science 275 : 661-665

6. Cross DA, Alessi DR, Cohen P, Andjelkovich M and Hemmings BA (1995) Links inhibition of glycogen synthase kinase-3 by insulin mediated by protein kinase B. Nature 378: 785-789

7. del Peso L, Gonzalez-Garcia M, Page C, Herrera R and Nunez G (1997) Interleukin-3-induced phosphorylation of BAD through the protein kinase Akt. Science 278: 687-689

8. Datta SR, Dudek H, Tao X, Masters S, Fu H, Gotoh Y and Greenberg ME (1997) Akt phosphorylation of BAD couples survival signals to the cell-intrinsic death machinery. Cell 91: 231-241

9. Rena G, Guo S, Cichy SC, Unterman TG and Cohen P (1999) Phosphorylation of the transcription factor forkhead family member FKHR by protein kinase B. J. Biol. Chem. 274: 17179-17183

10. Kops GJ, de Ruiter ND, De Vries-Smits AM, Powell DR, Bos JL and Burgering BM (1999) Direct control of the Forkhead transcription factor AFX by protein kinase B. Nature 398: 630-634

11. Brunet A, Bonni A, Zigmond MJ, Lin MZ, Juo P, Hu LS, Anderson MJ, Arden KC, Blenis J and Greenberg ME (1999) Akt promotes cell survival by phosphorylating and inhibiting a Forkhead transcription factor. Cell 96: 857-868

12. Cardone MH, Roy N, Stennicke HR, Salvesen GS, Franke TF, Stanbridge E, Frisch S and Reed JC (1998) Regulation of cell death protease caspase-9 by phosphorylation. Science 282: 1318-1321

13. Andjelkovic M, Alessi DR, Meier R, Fernandez A, Lamb NJ, Frech M, Cron P, Cohen P, Lucocq JM and Hemmings BA (1997) Role of translocation in the activation and function of protein kinase B. J. Biol. Chem. 272: 31515-31524

14. Meier R, Alessi DR, Cron P, Andjelkovic M and Hemmings BA (1997) Mitogenic activation, phosphorylation, and nuclear translocation of protein kinase Bbeta. J. Biol. Chem. 272: 30491-30497

15. Franke TF, Kaplan DR, Cantley LC and Toker A (1997) Direct regulation of the Akt proto-oncogene product by phosphatidylinositol-3,4-bisphosphate. Science 275: $665-668$

16. Alessi DR, Andjelkovic M, Caudwell B, Cron P, Morrice N, Cohen P and Hemmings BA (1996) Mechanism of activation of protein kinase $B$ by insulin and IGF-1. EMBO J. 15: 6541-6551

17. Alessi DR, James SR, Downes CP, Holmes AB, Gaffney PR, Reese CB and Cohen P. (1997) Characterization of a 3-phosphoinositide-dependent protein kinase which phosphorylates and activates protein kinase Balpha. Curr. Biol. 7: 261-269

18. Stokoe D, Stephens LR, Copeland T, Gaffney PR, Reese CB, Painter GF, Holmes AB, McCormick $F$ and Hawkins PT (1997) Dual role of phosphatidylinositol-3,4,5-trisphosphate in the activation of protein kinase $B$. Science 277: 567-570

19. Balendran A, Casamayor A, Deak M, Paterson A, Gaffney P, Currie R, Downes CP and Alessi DR (1999) PDK1 acquires PDK2 activity in the presence of a synthetic peptide derived from the carboxyl terminus of PRK2. Curr. Biol. 9: 393-404

20. Andjelkovic M, Jakubowicz T, Cron P, Ming XF, Han JW and Hemmings BA (1996) Activation and phosphorylation of a pleckstrin homology domain containing protein kinase (RAC-PK/PKB) promoted by serum and protein phosphatase inhibitors. Proc. Natl. Acad. Sci. USA 93: 5699-5704

21. Meier R, Thelen M and Hemmings BA (1998) Inactivation and dephosphorylation of protein kinase Balpha (PKBalpha) promoted by hyperosmotic stress. EMBO J. 17: 7294-7303

22. Chen D, Fucini RV, Olson AL, Hemmings BA and Pessin JE (1999) Osmotic shock inhibits insulin signaling by maintaining Akt/protein kinase $B$ in an inactive dephosphorylated state. Mol. Cell. Biol. 19: 4684-4694

23. Ivaska J, Nissinen L, Immonen N, Eriksson JE, Kahari VM and Heino J (2002) Integrin alpha 2 beta 1 promotes activation of protein phosphatase $2 \mathrm{~A}$ and dephosphorylation of Akt and glycogen synthase kinase 3 beta. Mol. Cell Biol. 22: $1352-1359$

24. Resjo S, Goransson O, Harndahl L, Zolnierowicz S, Manganiello V, Degerman $E$ (2002) Protein phosphatase $2 A$ is the main phosphatase involved in the regulation of protein kinase $B$ in rat adipocytes. Cell Signal. 14: 231-238

25. Groves MR, Hanlon N, Turowski $P$, Hemmings $B A$ and Barford D (1999) The structure of the protein phosphatase 2A PR65/A subunit reveals the conformation of its 15 tandemly repeated HEAT motifs. Cell 96 : 99-110

26. Chen J, Martin BL and Brautigan DL (1992) Regulation of protein serinethreonine phosphatase type-2A by tyrosine phosphorylation. Science 257 : 1261-1264

27. Chen J, Parsons S and Brautigan DL (1994) Tyrosine phosphorylation of protein phosphatase $2 \mathrm{~A}$ in response to growth stimulation and V-src transformation of fibroblasts. J. Biol. Chem. 269: 7957-7962

28. Srinivasan M and Begum N (1994) Stimulation of protein phosphatase-1 activity by phorbol esters. Evaluation of the regulatory role of protein kinase $\mathrm{C}$ in insulin action. J. Biol. Chem. 269: 12514-12520

29. Favre B, Zolnierowicz S, Turowski $P$ and Hemmings BA (1994) The catalytic subunit of protein phosphatase $2 \mathrm{~A}$ is carboxyl-methylated in vivo. J. Biol. Chem. 269: 16311-16317

30. De Baere I, Derua R, Janssens V, Van Hoof C, Waelkens E, Merlevede W and Goris J (1999) Purification of porcine brain protein phosphatase 2A leucine carboxyl methyltransferase and cloning of the human homologue. Biochemistry 38: $16539-16547$

31. Tolstykh T, Lee J, Vafai S and Stock JB (2000) Carboxyl methylation regulates phosphoprotein phosphatase $2 \mathrm{~A}$ by controlling the association of regulatory $\mathrm{B}$ subunits. EMBO J. 19: 5682-5691

32. Zhu T, Matsuzawa S, Mizuno Y, Kamibayashi C, Mumby MC, Andjelkovic N, Hemmings BA, Onoe $\mathrm{K}$ and Kikuchi K (1997) The interconversion of protein phosphatase $2 \mathrm{~A}$ between $\mathrm{PP} 2 \mathrm{~A} 1$ and $\mathrm{PP} 2 \mathrm{~A} 0$ during retinoic acid-induced granulocytic differentiation and a modification on the catalytic subunit in S phase of HL-60 cells. Arch. Biochem. Biophys. 339: 210-217

33. Wu J, Tolstykh T, Lee J, Boyd K, Stock JB and Broach JR (2000) Carboxyl methylation of the phosphoprotein phosphatase $2 A$ catalytic subunit promotes its functional association with regulatory subunits in vivo. EMBO J. 19: $5672-5681$

34. Westphal RS, Coffee Jr. RL, Marotta A, Pelech SL and Wadzinski BE (1999) Identification of kinase-phosphatase signaling modules composed of p70 S6 kinase-protein phosphatase $2 \mathrm{~A}$ (PP2A) and p21-activated kinase-PP2A. J. Biol. Chem. 274: 687-692

35. Westphal RS, Anderson KA, Means AR and Wadzinski BE (1998) A signaling complex of $\mathrm{Ca}^{2+}$-calmodulin-dependent protein kinase IV and protein phosphatase 2A. Science 280: 1258-1261

36. Liu W, Akhand AA, Kato M, Yokoyama I, Miyata T, Kurokawa K, Uchida K and Nakashima I (1999) 4-hydroxynonenal triggers an epidermal growth factor receptor-linked signal pathway for growth inhibition. J. Cell. Sci. 112: 2409-2417

37. Liu W, Kato M, Akhand AA, Hayakawa A, Suzuki H, Miyata T, Kurokawa K, Hotta Y, Ishikawa N and Nakashima I (2000) 4-hydroxynonenal induces a cellular redox status-related activation of the caspase cascade for apoptotic cell death. J. Cell. Sci. 113: 635-641

38. Hastie CJ and Cohen PT (1998) Purification of protein phosphatase 4 catalytic subunit: inhibition by the antitumour drug fostriecin and other tumour suppressors and promoters. FEBS Lett. 431: 357-361

39. Schonthal AH.(1998) Role of PP2A in intracellular signal transduction pathways. Front. Biosci. 3:1262-1273

40. Uzunoglu S, Uslu R, Tobu M, Saydam G, Terzioglu E, Buyukkececi F and Omay SB (1999) Augmentation of methylprednisolone-induced differentiation of myeloid leukemia cells by serine/threonine protein phosphatase inhibitors. Leukemia Res. 23:507-512

41. Shanley TP, Vasi N, Denenberg A and Wong HR (2001) The serine/threonine phosphatase, PP2A: endogenous regulator of inflammatory cell signaling. J. Immunol. 166: 966-972

42. Turowski P, Favre B, Campbell KS, Lamb NJ and Hemmings BA (1997) Modulation of the enzymatic properties of protein phosphatase $2 \mathrm{~A}$ catalytic subunit by the recombinant $65-k D a$ regulatory subunit PR65alpha. Eur. J. Biochem. 248: 200-208

43. Santoro MF, Annand RR, Robertson MM, Peng YW, Brady MJ, Mankovich JA, Hackett MC, Ghayur T, Walter G, Wong WW and Giegel DA (1998) Regulation of protein phosphatase $2 \mathrm{~A}$ activity by caspase- 3 during apoptosis. J. Biol. Chem. 273: 13119-13128

44. Hiraga $A$ and Tamura $S(2000)$ Protein phosphatase $2 A$ is associated in an inactive state with microtubules through $2 \mathrm{~A} 1$-specific interaction with tubulin. Biochem. J. 346: 433-439 
45. Sontag E, Nunbhakdi-Craig V, Lee G, Brandt R, Kamibayashi C, Kuret J, White III CL, Mumby MC and Bloom GS (1999) Molecular interactions among protein phosphatase $2 \mathrm{~A}$, tau, and microtubules. Implications for the regulation of tau phosphorylation and the development of tauopathies. J. Biol. Chem. 274: 25490-25498

46. Sontag E, Nunbhakdi-Craig V, Bloom GS and Mumby MC (1995) A novel pool of protein phosphatase $2 A$ is associated with microtubules and is regulated during the cell cycle. J. Cell. Biol. 128: 1131-1144

47. O'toole A, Moule SK, Lockyer PJ and Halestrap AP (2001) Tumour necrosis factor-alpha activation of protein kinase B in WEHI-164 cells is accompanied by increased phosphorylation of Ser473, but not Thr308. Biochem. J. 359: 119-127

48. Kishikawa K, Chalfant CE, Perry DK, Bielawska A and Hannun YA (1999) Phosphatidic acid is a potent and selective inhibitor of protein phosphatase 1 and an inhibitor of ceramide-mediated responses. J. Biol. Chem. 274: 21335-21341

49. Guo H and Damuni Z (1993) Autophosphorylation-activated protein kinase phosphorylates and inactivates protein phosphatase 2A. Proc. Natl. Acad. Sci. USA. 90: 2500-2504

50. Karni $R$ and Levitzki A (2000) pp60(cSrc) is a caspase-3 substrate and is essential for the transformed phenotype of A431 cells. Mol. Cell. Biol. Res. Commun. 3: 98-104
51. Uchida K, Toyokuni S, Nishikawa K, Kawakishi S, Oda H, Hiai H and Stadtman ER (1994) Michael addition-type 4-hydroxy-2-nonenal adducts in modified lowdensity lipoproteins: markers for atherosclerosis. Biochemistry 33: 12487-12494

52. Traverso N, Menini S, Cosso L, Odetti P, Albano E, Pronzato MA and Marinari UM (1998) Immunological evidence for increased oxidative stress in diabetic rats. Diabetologia 41: 265-270

53. Sayre LM, Zelasko DA, Harris PL, Perry G, Salomon RG and Smith MA (1997) 4-Hydroxynonenal-derived advanced lipid peroxidation end products are increased in Alzheimer's disease. J. Neurochem. 68: 2092-2097

54. Montine TJ, Montine KS and Swift LL (1997) Central nervous system lipoproteins in Alzheimer's disease. Am. J. Pathol. 150: 437-443

55. Uchida K, Shiraishi M, Naito Y, Torii Y, Nakamura Y and Osawa T (1999) Activation of stress signaling pathways by the end product of lipid peroxidation. 4-hydroxy-2-nonenal is a potential inducer of intracellular peroxide production. J. Biol. Chem. 274: 2234-2242

56. Lipsich LA, Lewis AJ and Brugge JS (1983) Isolation of monoclonal antibodies that recognize the transforming proteins of avian sarcoma viruses. J. Virol. 48: 352-360 